\title{
Age, physical fitness, and attention: P3a and P3b
}

\author{
MATTHEW B. PONTIFEX, ${ }^{a}$ CHARLES H. HILLMAN, ${ }^{a}$ AND JOHN POLICH ${ }^{\mathrm{b}}$ \\ ${ }^{a}$ University of Illinois at Urbana-Champaign, Urbana, Illinois, USA \\ ${ }^{\mathrm{b}}$ The Scripps Research Institute, La Jolla, California, USA
}

\begin{abstract}
The influence of age and fitness on the neuroelectric correlates of attentional orienting and processing during stimulus discrimination were investigated. Younger and older adult participants completed a maximal aerobic exercise test and were separated into higher- and lower-fit groups according to their cardiorespiratory fitness. Task performance and event-related potential measures were obtained during two- and three-stimulus oddball tasks. Results indicated that fitness may ameliorate or protect against cognitive aging for simple stimulus discriminations. Increases in task difficulty indicated that fitness may not be sufficient to overcome age-related deficits in stimulus discrimination. Further, fitness did not influence attentional orienting. The findings suggest that fitness-related changes in cognitive function may originate from other attentional mechanisms. Theoretical implications are discussed.
\end{abstract}

Descriptors: Age, Fitness, Stimulus discrimination, Attentional orienting, Task difficulty, P300, P3a, P3b.

The relationship between fitness and cognitive aging has been increasingly assessed over the past decade. A major question is how health-oriented behaviors can mitigate age-related cognitive decline, with recent evidence indicating that participation in aerobic exercise may ameliorate or protect against declines in the brain (Colcombe et al., 2004; Cotman \& Engesser-Cesar, 2002) and cognitive function (Colcombe \& Kramer, 2003; Hillman, Erickson, \& Kramer, 2008; Hillman et al., 2006b; Kramer \& Erickson, 2007) associated with aging. Initial articulation of how the neural mechanisms underlying fitness-induced changes in cognition have been obtained using event-related brain potential (ERP) methods (see Hillman, Buck, \& Themanson, in press, for a review). Specifically, fitness-related changes in cognition may result in part from changes in the attention system that contributes to the P300 (P3b) component (see Kramer \& Hillman, 2006, for a review). When coupled with recent neuroanatomical evidence indicating age-related atrophy of the neural network involved in attentional control (Milham et al., 2002), ERPs can serve to provide insight into the nature of exercise effects on cognition.

\section{P3a and P3b}

The $\mathrm{P} 300$ is a large positive-going peak occurring approximately 300 to $800 \mathrm{~ms}$ following stimulus onset and reflects attentional processes as indexed by two subcomponents, the "P3a" and

We would like to thank the National Institute on Aging (R01 AG021188) for their support of our research and the preparation of this manuscript.

Address reprint requests to: Charles H. Hillman, Ph.D., Department of Kinesiology \& Community Health, 317 Louise Freer Hall, 906 South Goodwin Avenue, University of Illinois, Urbana, IL 61801. E-mail: chhillma@illinois.edu
"P3b" that represent distinct but related neural processes. These ERPs are distinguished by the context in which a stimulus occurs, which governs component amplitude size and distribution across the scalp. In the absence of task directions, an infrequent or a physically "alerting" distracter can elicit a P3a component characterized by fronto-central topographic maximum and relatively short peak latency. When a participant is instructed to respond to an infrequently presented target stimulus in a single-stimulus or a two-stimulus oddball discrimination task, the P3b component is elicited with maximum amplitude over the parietal cortex (Donchin, Karis, Bashore, Coles, \& Gratton, 1986; Johnson, 1993).

The P3a is hypothesized to be associated with the selection of stimulus information governed by attentional orienting (Knight, 1984; Kok, 2001; Rushby, Barry, \& Doherty, 2005), such that it reflects the disengagement of previous attentional focus to reengage attentional processes toward the infrequent stimulus (Squires, Squires, \& Hillyard, 1975). P3a amplitude therefore can index attentional orienting with increased amplitude related to greater focal attention (Polich, 2007). The P3b is thought to reflect neuronal activity associated with revision of the mental representation of the previous event within the stimulus environment (Donchin, 1981). Its amplitude is determined by the allocation of attentional resources when working memory is updated (Donchin \& Coles, 1988), so that P3b is sensitive to the amount of attentional resources allocated to a stimulus (Polich, 1987; Polich \& Heine, 1996). P3b timing marked by its peak latency is generally considered to represent stimulus evaluation and classification speed (Duncan-Johnson, 1981; Kutas, McCarthy, \& Donchin, 1977). Component latency therefore can be used as a measure of stimulus detection and evaluation time (Ilan \& Polich, 1999; Magliero, Bashore, Coles, \& Donchin, 1984), which is often independent of response selection and behavioral action (Verleger, 1997). 


\section{Aging and P300}

ERPs as a measure of neural activity appear to be a sensitive index of changes in cognition associated with aging (Goodin, Squires, Henderson, \& Starr, 1978). P300 has proven to be a useful tool in characterizing age-related changes in cognition with both the $\mathrm{P} 3 \mathrm{a}$ and $\mathrm{P} 3 \mathrm{~b}$ components exhibiting robust agerelated reductions in amplitude and slowing of latency across multiple tasks and populations (Anderer, Semlitsch, \& Saletu, 1996; Celesia, 1986; Fjell \& Walhovd, 2001; Friedman, Simpson, \& Hamberger, 1993; Polich, 1996; Picton, Stuss, Champagne, \& Nelson, 1984). These P300 age-related changes may reflect deficits in the underlying processes such as degeneration of the functional cortical interconnection that occur with age (Bashore \& Ridderinkhof, 2002; Reuter-Lorenz, 2002), resulting in a reduced ability to orient attention and suppress extraneous neuronal operations to facilitate attentional processing. This assertion is consonant with the hypothesis that neural inhibition underlies $\mathrm{P} 3 \mathrm{a} / \mathrm{P} 3 \mathrm{~b}$ generation, such that component amplitude indexes the suppression of extraneous neuronal activity: P3a indexes engagement of focal attention, and $\mathrm{P} 3 \mathrm{~b}$ indexes attentional resource allocation and subsequent memory processing (Azizian \& Polich, 2007; Hartikainen \& Knight, 2003; Kok, 2001).

Previous studies using neuroelectric measures have begun to elucidate the mechanisms engaged by the beneficial relationship between physical activity and cognitive health during aging (Kramer \& Hillman, 2006; Hillman, Weiss, Hagberg, \& Hatfield, 2002; Hillman, Belopolsky, Snook, Kramer, \& McAuley, 2004; Hillman, Kramer, Belopolsky, \& Smith, 2006a; Hillman et al., 2008). For example, increased P3b amplitude has been observed for high physically active participants relative to their low active counterparts using auditory and visual stimulus discrimination tasks (Polich \& Lardon, 1997). Similar findings have suggested a positive association between physical activity or aerobic fitness and cognitive aging (Hillman et al., 2002, 2004, 2006a). Given a neural inhibition genesis for $\mathrm{P} 300$, it is reasonable to suppose that aerobic fitness promotes an increased ability to inhibit neuronal activity unrelated to task performance, which would facilitate stimulus evaluation to increase P300 amplitude and decrease its latency.

\section{Present Study}

The present study assessed this possibility by manipulating attentional processing demands across age and fitness. The goal was to determine whether fitness is related to a general change in the attentional system or whether it is selective to a specific aspect of attention. Toward this end, well-studied ERP tasks that varied perceptual task difficulty were employed to elicit reliable P3a and P3b components (Conroy \& Polich, 2007; Walhovd, Rosquist, \& Fjell, 2008). This approach permitted direct evaluation of theoretically well-developed techniques to assay attention allocation. It was hypothesized that age would be associated with reduced amplitude and longer latency for both the P3a and P3b components as found previously. Further, regardless of age, higher-fit participants should demonstrate an increased ability to orient attention as reflected by relatively larger P3a amplitudes and allocate attention during the discrimination task as reflected by larger P3b amplitudes. In addition, these individuals should demonstrate faster stimulus evaluation and classification speed as indexed by shorter P3b latency, with facilitation of behavioral performance relative to lower-fit participants.

\section{Method}

\section{Participants}

Table 1 summarizes the demographic and fitness data for all participants. A total of 48 (29 female) younger (18-22 years) and older (61-73 years) participants from the East Central Illinois area was recruited based on aerobic fitness. Older adult participants were solicited from two ongoing clinical trials, whereas younger adult participants were obtained from the local undergraduate student population. All participants provided written informed consent that was approved by the Institutional Review Board of the University of Illinois at Urbana-Champaign and reported being free of neurological disorders, cardiovascular disease, any medications that influence central nervous system function, and had (corrected to) normal vision based on the minimal 20/20 standard.

\section{Cardiorespiratory Fitness Assessment}

Prior to participation, all older adult participants were cleared to participate by their primary care physician. Maximal aerobic power $\left(\mathrm{VO}_{2 \max }\right)$ was measured using a motor-driven treadmill by employing a modified Balke protocol (ACSM, 2000), which involved walking/running on a treadmill at a constant speed with increasing grade increments of $2 \%$ every two min until volitional exhaustion. A computerized indirect calorimetry system (ParvoMedics True Max 2400, Sandy, UT) collected 30-s averages for oxygen uptake $\left(\mathrm{VO}_{2}\right)$ and respiratory exchange ratio (RER). Young adult heart rate (HR) was assessed using a Polar HR

Table 1. Participant Demographics and Fitness Values

\begin{tabular}{|c|c|c|c|c|}
\hline \multirow[b]{2}{*}{ Measure } & \multicolumn{2}{|c|}{ Younger adults } & \multicolumn{2}{|c|}{ Older adults } \\
\hline & Higher-fit & Lower-fit & Higher-fit & Lower-fit \\
\hline N (Female) & $12(\mathrm{~F}=7)$ & $13(\mathrm{~F}=9)$ & $10(\mathrm{~F}=5)$ & $13(\mathrm{~F}=8)$ \\
\hline Mean age (yrs) & $20.3 \pm 1.1^{\mathrm{a}}$ & $20.1 \pm 1.5^{\mathrm{a}}$ & $66.2 \pm 3.5^{b}$ & $67.4 \pm 3.2^{\mathrm{b}}$ \\
\hline Age range (yrs) & $19-22$ & $18-23$ & $61-73$ & $62-73$ \\
\hline $\mathrm{VO}_{2} \max$ & $56.7 \pm 8.0^{\mathrm{a}}$ & $31.8 \pm 2.4^{\mathrm{b}}$ & $36.6 \pm 3.5^{\mathrm{b}}$ & $20.3 \pm 2.7^{\mathrm{c}}$ \\
\hline BMI $\left(\mathrm{kg} / \mathrm{m}^{2}\right)$ & $21.2 \pm 0.4^{\mathrm{a}}$ & $22.1 \pm 1.5^{\mathrm{a} / \mathrm{b}}$ & $24.7 \pm 1.1^{\mathrm{b} / \mathrm{c}}$ & $26.8 \pm 0.9^{\mathrm{c}}$ \\
\hline Cerebral vascular risk factors & $0.2 \pm 0.1^{\mathrm{a}}$ & $0.2 \pm 0.1^{\mathrm{a}}$ & $1.0 \pm 0.3^{\mathrm{b}}$ & $1.1 \pm 0.3^{\mathrm{b}}$ \\
\hline Education (yrs) & $14.3 \pm 0.4^{\mathrm{a}}$ & $14.4 \pm 0.4^{\mathrm{a}}$ & $16.0 \pm 1.0^{\mathrm{a}}$ & $15.5 \pm 0.7^{\mathrm{a}}$ \\
\hline K-BIT (IQ) & - & - & $112.8 \pm 3.9^{\mathrm{a}}$ & $111.2 \pm 2.7^{\mathrm{a}}$ \\
\hline Beck Depression Inventory & - & - & $4.9 \pm 1.3^{\mathrm{a}}$ & $3.9 \pm 0.8^{\mathrm{a}}$ \\
\hline Mini Mental Status Exam & - & - & $28.7 \pm 0.4^{\mathrm{a}}$ & $28.4 \pm 0.3^{\mathrm{a}}$ \\
\hline
\end{tabular}

Note: K-BIT is a composite score for IQ. Cerebral vascular risk factors is the total number of risk factors defined as hypertension, dyslipidemia, impaired fasting glucose, obesity, carotid, or peripheral artery disease, previous incidence of atrial fibrillation, transient ischemic attack, stroke, or heart attack. Values that share a common superscript are not significantly different at $p \leq .05$. 
monitor (Model A1, Polar Electro, Finland), and older adult HR was assessed using a 12-lead EKG. Both groups reported their rating of perceived exertion (RPE) at the completion of each twomin stage (Borg, 1970). Relative peak oxygen consumption was expressed in $\mathrm{ml} / \mathrm{kg} / \mathrm{min}$ and was derived from a measure of maximal effort when the participants achieved two of the following four criteria: (1) reached a plateau in oxygen consumption corresponding to an increase of less than $2 \mathrm{ml} / \mathrm{kg} / \mathrm{min}$ despite an increase in workload; (2) HR was within 10 beats per min (bpm) of age-predicted maximum (i.e., 220-age); (3) respiratory exchange ratio was $\geq 1.10$; or (4) perceived exertion was $\geq 17$.

\section{ERP Tasks}

A two-stimulus classic easy discrimination visual oddball and three-stimulus difficult visual discrimination task were employed in separate conditions. The oddball task was designed to elicit a typical P3b (canonical P300), whereas the three-stimulus task was employed to produce a reliable $\mathrm{P} 3 \mathrm{a}$ from a consistent distracter and $\mathrm{P} 3 \mathrm{~b}$ from the target. These methods have proven useful for assessing both normal and clinical populations (Polich, 2004), with the theoretical account of attention and memory events reflected by the separate subcomponents (Polich, 2008).

Oddball Task

A visual oddball task was used in which participants were asked to respond as quickly and accurately as possible with a right hand thumb press only to the randomly occurring target in a series of non-target stimuli. Target stimuli were $5.5 \mathrm{~cm}$ diameter white circles that occurred with a probability of 0.20 , and nontarget stimuli were $3 \mathrm{~cm}$ diameter white circles that occurred with a probability of 0.80 . Three counterbalanced blocks of 200 trials were presented centrally on a computer monitor at a distance of 1 meter on a black background. The stimulus occurred for $100 \mathrm{~ms}$ presentation duration, with a $1000 \mathrm{~ms}$ response window and a $2000 \mathrm{~ms}$ inter-trial interval.

\section{Three-Stimulus Task}

A visual three-stimulus oddball task had participants respond as quickly and accurately as possible with a right hand thumb press only to the randomly occurring target stimulus while ignoring all other stimuli (Hagen, Gatherwright, Lopez, \& Polich, 2006). Target stimuli were $5.5 \mathrm{~cm}$ diameter white circles that occurred with a probability of 0.12 , and non-target stimuli were 5.0 $\mathrm{cm}$ diameter white circles that occurred with a probability of 0.76 . In addition to the increased difficulty in discriminating between target and non-target stimuli, a "distracter" stimulus also was presented, which was a black and white checkerboard pattern consisting of $2.0 \mathrm{~cm}$ square blocks occurring with a probability of 0.12 . Three counterbalanced blocks of 200 trials were presented focally on a computer monitor at a distance of $1 \mathrm{~m}$. All stimuli were presented on a black background for $100 \mathrm{~ms}$ duration, with a $1000 \mathrm{~ms}$ response window and a $2000 \mathrm{~ms}$ inter-trial interval.

\section{ERP Recording}

Electroencephalographic (EEG) activity was recorded from 64 electrode sites (FPz, Fz, FCz, Cz, CPz, Pz, POz, Oz, FP1/2, F7/ 5/3/1/2/4/6/8, FT7/8, FC3/1/2/4, T7/8, C5/3/1/2/4/6, M1/2, TP7/8, CB1/2, P7/5/3/1/2/4/6/8, PO $7 / 5 / 3 / 4 / 6 / 8, \mathrm{O} 1 / 2)$ of the International 10-20 system (Jasper, 1958), using a Neuroscan Quik-cap, referenced to averaged mastoids (M1, M2), with AFz serving as the ground electrode, and impedance less than $10 \mathrm{k} \Omega$. Additional electrodes were placed above and below the left orbit and on the outer canthus of each eye to monitor electro-oculo- graphic (EOG) activity with a bipolar recording. Continuous data were digitized at a sampling rate of $500 \mathrm{~Hz}$, amplified 500 times with a DC to $70 \mathrm{~Hz}$ filter, and a $60 \mathrm{~Hz}$ notch filter using a Neuroscan Synamps 2 amplifier. Continuous data were corrected offline for EOG activity using a spatial filter (Compumedics Neuroscan, 2003). Epochs were created from -100 to $1000 \mathrm{~ms}$ around the stimuli and baseline corrected using the 100 $\mathrm{ms}$ pre-stimulus period. Data were filtered using a zero phase shift $30 \mathrm{~Hz}$ (24 dB/octave) low-pass filter. Trials with a response error or artifact exceeding $\pm 75 \mu \mathrm{V}$ were rejected. The $\mathrm{N} 1$ and $\mathrm{N} 2$ components were defined as the largest negative-going peaks occurring within 50-150 ms and 150-300 ms, respectively. The P2 and P3 components were defined as the largest positive-going peaks occurring within 150-300 $\mathrm{ms}$ and 300-700 ms, respectively. Amplitude was measured as the difference between the mean pre-stimulus baseline and maximum peak amplitude; peak latency was defined as the time point corresponding to the maximum amplitude.

\section{Procedure}

Day 1: Cardiorespiratory Fitness Assessment

On the first visit to the laboratory, participants completed an informed consent, health history and demographics questionnaire, and the Physical Activity Readiness Questionnaire (Thomas, Reading, \& Shephard, 1992) to screen for any previous health issues that might be exacerbated by acute exercise. Data on older adult participants were obtained from the ongoing clinical trials relative to the Mini Mental Status Exam (Folstein, Folstein, \& McHugh, 1975), Beck Depression Inventory (Beck, Ward, \& Mendelson, 1961), and the Kaufman Brief Intelligence Test (K-BIT; Kaufman \& Kaufman, 1990) to ensure that all older participants were free from dementia and depression, and had a normal intelligence quotient (IQ), respectively. Participants were then fitted with a Polar HR monitor (younger) or 12lead EKG (older) and had their height and weight measured using a stadiometer and a Tanita BWB-600 digital scale, respectively. Following a brief warm-up period, participants exercised at an increasing workload until volitional exhaustion. Following the cardiorespiratory fitness assessment, participants were given a cool-down period and waited for their HR to return to within $10 \mathrm{bpm}$ of their resting HR prior to leaving. Participants were then invited to participate in the second day of testing if their $\mathrm{VO}_{2 \max }$ fell above the 70th percentile or below the 30th percentile according to the American College of Sports Medicine's Guidelines for Exercise Testing and Prescription 6th edition.

\section{Day 2: Experimental Ssession}

On the second visit, participants completed an Edinburgh handedness inventory (Oldfield, 1971) prior to neuroelectric testing, which was conducted in a sound attenuated room. Participants were assessed using one of three trial orders that were counterbalanced within subject groups. Each individual was fitted with a 64-channel Quik-cap (Compumedics Neuroscan, El Paso, TX). Participants were read task instructions and given 16 practice trials before each task. Upon completion of the last condition, all electrodes were removed and participants were briefed on the purpose of the experiment.

\section{Statistical Analysis}

Inter-task difficulty was assessed using a 2 (age: younger, older) $\times 2$ (fitness: higher-fit, lower-fit) $\times 2$ (task: oddball vs. threestimulus) univariate repeated measures ANOVA performed on 
the response accuracy and response time (RT) data from the target stimulus for each task. Performance accuracy and RT data were also analyzed separately for each task using a 2 (age: younger, older) $\times 2$ (fitness: higher-fit, lower-fit) univariate repeated measures ANOVA. For ERP values, statistical analyses were performed on data from the seven midline $(\mathrm{Fz}, \mathrm{FCz}, \mathrm{Cz}$, $\mathrm{CPz}, \mathrm{Pz}, \mathrm{POz}, \mathrm{Oz}$ ) electrode sites. Omnibus analyses were conducted separately for each ERP component and for amplitude and latency values. ERP component values for each participant were submitted to a 2 (age: younger, older) $\times 2$ (fitness: higherfit, lower-fit) $\times 7$ (electrode site: Fz, FCz, Cz, CPz, Pz, POz, Oz) univariate repeated measures ANOVA. All analyses used a significance level of $p=.05$, and analyses with three or more withinsubjects levels used the Greenhouse-Geisser statistic. Multiple probability corrected post hoc $t$-tests were conducted using Tukey's honestly significant difference procedure.

\section{Results}

\section{Task Performance}

Oddball vs. Three-Stimulus Tasks

The two-stimulus oddball task yielded fewer errors than the three-stimulus task $(5.4 \%$ vs. $26.9 \%), F(1,44)=71.2, p<.001$, $\eta^{2}=.62$. The oddball task demonstrated shorter RT than the three-stimulus task to target stimuli (359 vs. $482 \mathrm{~ms})$, $F(1,44)=253.0, p<.001, \eta^{2}=.85$. No reliable interactions involving task difficulty were obtained for the age or fitness factors. Thus, discrimination difficulty was successfully manipulated between the task conditions.

\section{Accuracy}

No significant age or fitness effects were observed within either the oddball task, $F(1,44) \leq 2.0, p \geq .17, \eta^{2} \leq .05$ (all comparisons), nor the three stimulus task, $F(1,44) \leq 2.4, p \geq .13$, $\eta^{2} \leq .05$ (all comparisons).

\section{Response time}

Table 2 summarizes the RT to the oddball target stimulus for each aerobic fitness and age group. Target stimuli from the oddball task yielded shorter RTs for the younger $(\mathrm{M}=338$, $\mathrm{SE}=10.7 \mathrm{~ms})$ compared to the older $(\mathrm{M}=380, \mathrm{SE}=11.3 \mathrm{~ms})$ participants, $F(1,44)=7.3, p<.05, \eta^{2}=.14$, and for higher-fit $(\mathrm{M}=343, \mathrm{SE}=11.5 \mathrm{~ms})$ relative to lower fit $(\mathrm{M}=375$, $\mathrm{SE}=10.5 \mathrm{~ms}$ ) participants, $F(1,44)=4.1, p=.05, \eta^{2}=.08$. Target stimuli from the three-stimulus task yielded shorter RT for the younger $(\mathrm{M}=465, \mathrm{SE}=11.8 \mathrm{~ms})$ compared to older $(\mathrm{M}=499, \mathrm{SE}=12.4 \mathrm{~ms})$ participants, $F(1,44)=4, p=.05$, $\eta^{2}=.08$. In sum, younger participants responded more quickly than older subjects.

\section{ERP Component Amplitude}

\section{N2 Amplitude}

Figure 1 illustrates the grand average ERP waveform for each age and fitness group. The oddball target as well as the three-

Table 2. Mean (+1 SE) RT to the Oddball Target Stimulus for Each Aerobic Fitness and Age Group

\begin{tabular}{lccccc}
\hline \hline \multirow{2}{*}{ Measure } & \multicolumn{2}{c}{ Younger adults } & & \multicolumn{2}{c}{ Older adults } \\
\cline { 2 - 3 } \cline { 5 - 6 } & Higher-fit & Lower-fit & & Higher-fit & Lower-fit \\
\hline RT (ms) & $318.7 \pm 13.0$ & $358.0 \pm 18.2$ & & $368.7 \pm 18.4$ & $392.0 \pm 11.9$ \\
\hline \hline
\end{tabular}

stimulus target/distracter stimuli demonstrated a reliable electrode site effect (oddball target: $F(6,39)=10.8, p<.001$, $\eta^{2}=.20$; three-stimulus target: $F(6,39)=5.6, p<.005, \eta^{2}=.11$; three-stimulus distracter: $\left.F(6,39)=5.3, p<.01, \eta^{2}=0.11\right)$. Component amplitude was differentially affected by age with respect to electrode site to yield a significant interaction between these factors (oddball target: $F(6,39)=5.3, p<.01, \eta^{2}=.11$; threestimulus target: $F(6,39)=3.1, p<.05, \eta^{2}=.07$; three-stimulus distracter: $\left.F(6,39)=3.9, p<.05, \eta^{2}=.08\right)$. Post hoc assessment of age within each site revealed increased amplitude for younger relative to older adults at the $\mathrm{Fz}$ and $\mathrm{FCz}$ electrode sites for the oddball target, $t(46) \geq 2.1, p<.05$. For the three-stimulus target, post hoc tests revealed increased amplitude for younger relative to older adults at the $\mathrm{Fz}, \mathrm{FCz}, \mathrm{Cz}$, and $\mathrm{CPz}$ electrode sites, $t(46) \geq 3, p \leq .005$ (all comparisons). For the three-stimulus distracter, age effects were not observed, $t(46) \leq 2.7, p \geq .01$ (all comparisons).

\section{P3b Amplitude}

Figure 2 illustrates the topographic amplitude maps for each P3 from each age and fitness group. Oddball target amplitude evinced age, $F(1,44)=16.7, p<.001, \quad \eta^{2}=.28$, and site, $F(6,39)=30.1, p<.001, \eta^{2}=.41$, main effects. These factors also demonstrated an age $\times$ site interaction, $F(6,39)=4.3$, $p<.05, \eta^{2}=.09$, such that larger amplitude was observed for younger relative to older adults from the frontal to occipital electrode sites, $t(46) \geq 2.5, p \leq .02$ (all comparisons). Figure 3 illustrates the overall target stimulus amplitude from the oddball task for the fitness main effect: higher-fit $(\mathrm{M}=15.4, \mathrm{SE}=1.0$ $\mu \mathrm{V})$ compared to lower-fit $(\mathrm{M}=11.9, \mathrm{SE}=0.9 \mu \mathrm{V})$ participants produced larger $\mathrm{P} 3 \mathrm{~b}$ component amplitudes, $F(1,44)=6.2$, $p<.05, \eta^{2}=.12$. The target from the three-stimulus task yielded main effects for age, $F(1,44)=4.3, p<.05, \eta^{2}=.09$, site, $F(6,39)=15.7, p<.001, \eta^{2}=.26$, and fitness, $F(1,44)=4$, $p=.05, \eta^{2}=.08$. These factors also produced a significant age $\times$ fitness interaction, $F(1,44)=7.5, p<.01, \eta^{2}=.15$, and an age $\times$ site interaction, $F(6,39)=5.5, p<.005, \eta^{2}=.11$. Figure 4 illustrates the age $\times$ fitness interaction, which demonstrated larger $\mathrm{P} 3 \mathrm{~b}$ amplitude for higher-fit younger adults $(\mathrm{M}=11.5$, $\mathrm{SE}=1.3 \mu \mathrm{V})$ relative to lower-fit younger adults $(\mathrm{M}=6.5$, $\mathrm{SE}=0.7 \mu \mathrm{V})$, whereas no fitness differences were observed between the higher-fit $(\mathrm{M}=6.4, \mathrm{SE}=0.8 \mu \mathrm{V})$ and the lower-fit $(\mathrm{M}=7.2, \mathrm{SE}=1.2 \mu \mathrm{V})$ older adults, $t(23) \geq 2.46, p \leq .02$. Follow up analysis of the age $\times$ site interaction by examining age within each site revealed larger amplitude at $\mathrm{Pz}$ and $\mathrm{POz}$ electrode sites for younger adults relative to older adults, $t(46) \geq 2.4$, $p \leq .02$ (both comparisons).

\section{P3a Amplitude}

Figure 2 illustrates the topographic amplitude maps for each P3 from each age and fitness group. The distracter from the three-stimulus task produced larger amplitudes for younger $(\mathrm{M}=26.0, \mathrm{SE}=1.3 \mu \mathrm{V})$ compared to older $(\mathrm{M}=21.2, \mathrm{SE}=1.4$ $\mu \mathrm{V})$ participants, $F(1,44)=6.7, p<.05, \eta^{2}=.13$. Follow-up analysis on the main effect of site revealed smaller amplitude at $\mathrm{Fz}$ relative to $\mathrm{FCz}, \mathrm{Cz}$, and $\mathrm{CPz}$ electrode sites, $t(47) \geq 5.6$, $p<.001$ (all comparisons); $\mathrm{Pz}$ relative to $\mathrm{Cz}$ and $\mathrm{CPz}$ electrode sites, $t(47) \geq 3.8, p<.001$ (all comparisons); $\mathrm{POz}$ relative to $\mathrm{FCz}, \mathrm{Cz}, \mathrm{CPz}$, and $\mathrm{Pz}$ electrode sites, $t(47) \geq 6.2, p<.001$ (all comparisons); $\mathrm{Oz}$ relative to $\mathrm{Fz}, \mathrm{FCz}, \mathrm{Cz}, \mathrm{CPz}, \mathrm{Pz}$, and $\mathrm{POz}$ electrode sites, $t(47) \geq 6.8, p<.001$ (all comparisons). 
Higher-Fit Younger Oddball Target
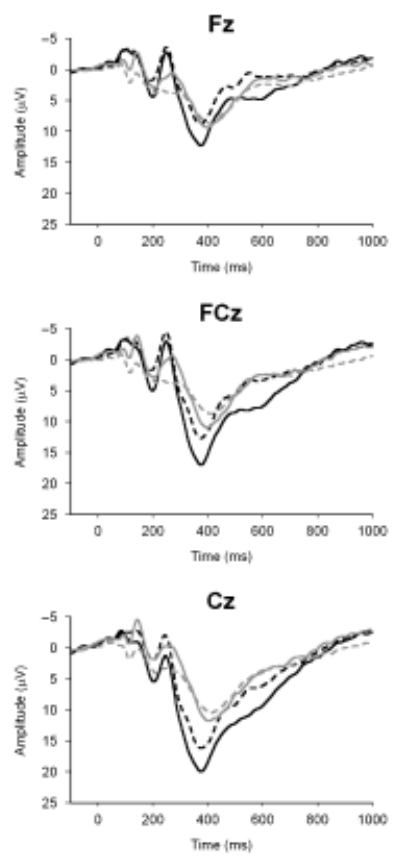

$\mathrm{CPz}$

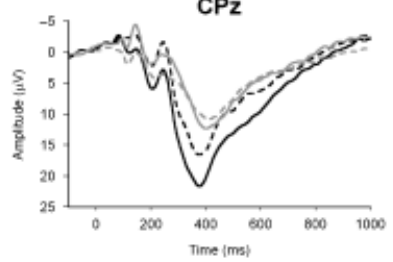

Pz

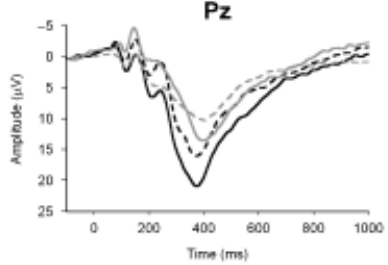

POz

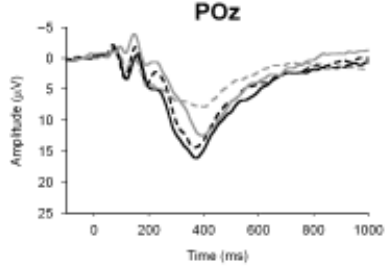

$\mathrm{Oz}$

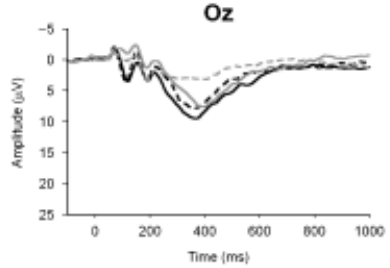

=E= Lower-Fit Younger Three-Stimulus Target

Fz
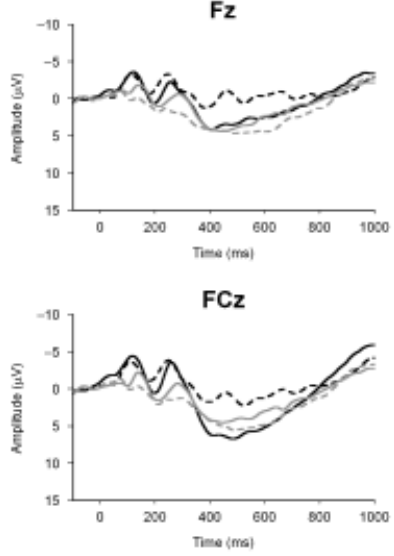

$\mathrm{Cz}$

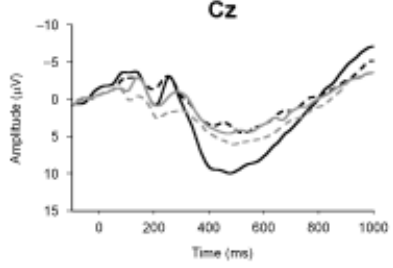

$\mathrm{CPz}$

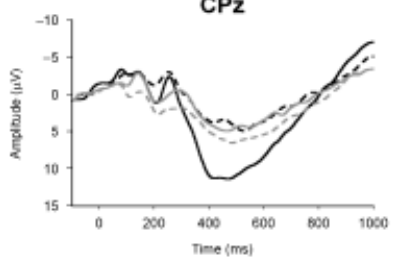

Pz

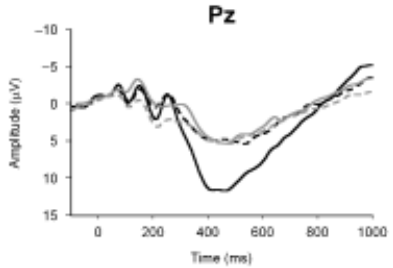

$\mathrm{POz}$

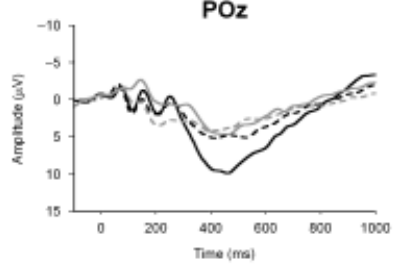

$\mathrm{Oz}$

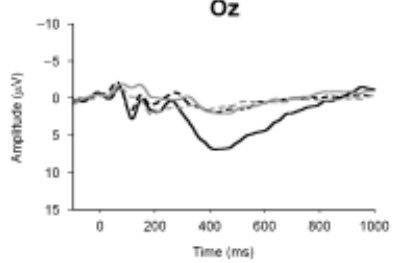

Higher-Fit Older $\quad=m= \pm$ Lower-Fit Older

Three-Stimulus Distracter
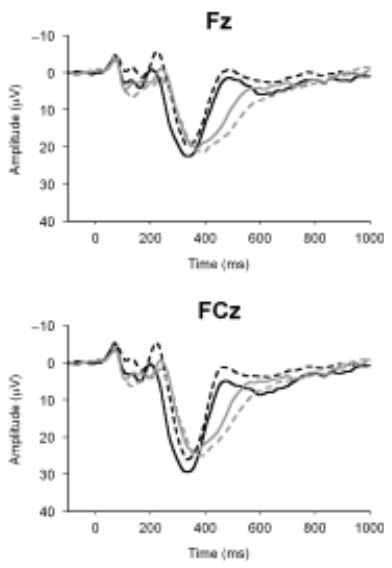

$\mathrm{Cz}$

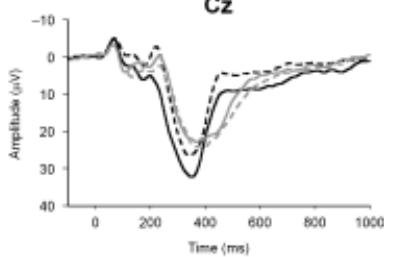

$\mathrm{CPz}$

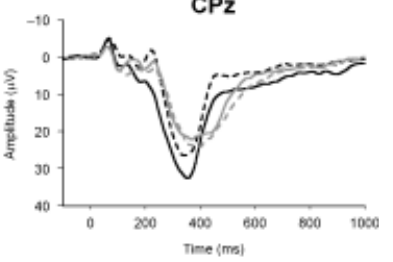

Pz

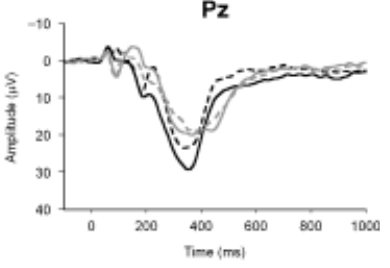

$\mathrm{POz}$

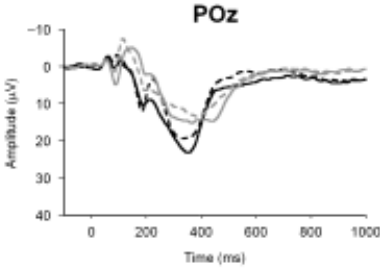

$\mathrm{Oz}$

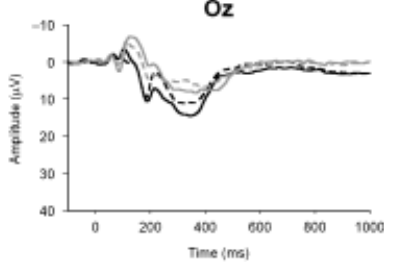

Figure 1. Grand average ERP waveforms for each age and fitness for each condition from each target and distracter stimulus. Note different voltage scales for each component/task. 


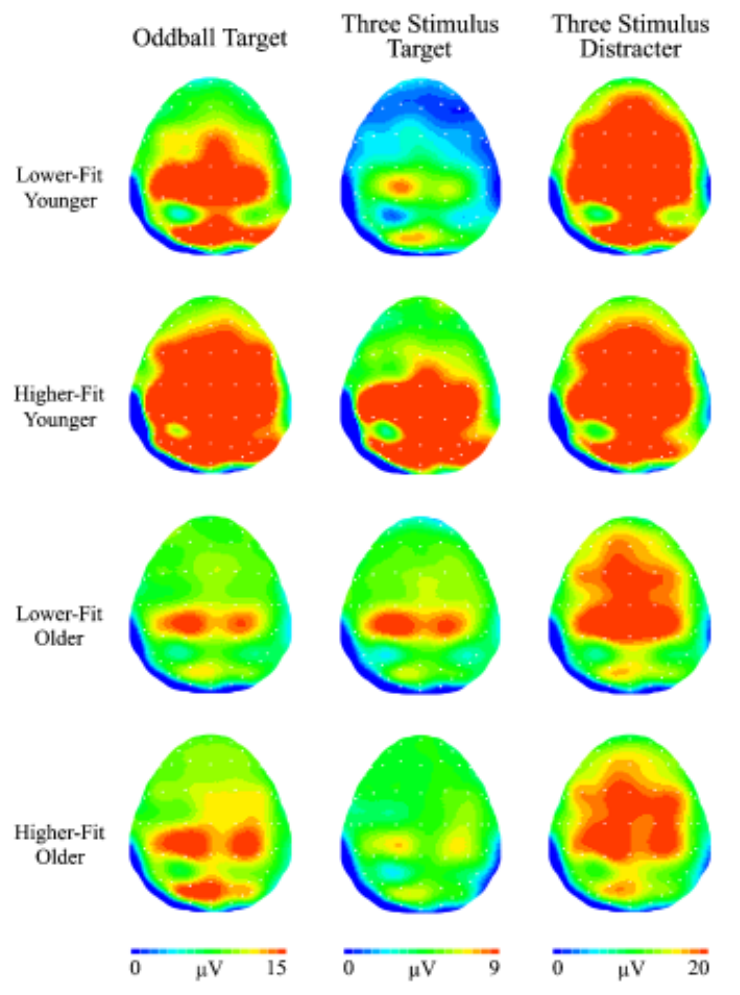

Figure 2. Topographic amplitude maps for the $\mathrm{P} 3 \mathrm{a}$ and $\mathrm{P} 3 \mathrm{~b}$ components for each age and fitness from each stimulus condition. Note different voltage scales for each task.

\section{ERP Component Latency}

\section{N2 Latency}

Oddball target $\mathrm{N} 2$ yielded a main effect of site, $F(6,39)=$ $9.81, p<.001, \eta^{2}=.18$, with post hoc tests indicating that $\mathrm{Pz}$ and $\mathrm{POz}$ exhibited shorter latency relative to $\mathrm{Fz}, \mathrm{FCz}, \mathrm{Cz}$, and $\mathrm{CPz}$ electrode sites, $t(47) \geq 3.4, p \leq .001$ (all comparisons). The three-stimulus target produced shorter N2 latencies for the younger $(\mathrm{M}=256, \mathrm{SE}=7.4 \mathrm{~ms})$ compared to older $(\mathrm{M}=278$, $\mathrm{SE}=7.8 \mathrm{~ms}$ ) participants, $F(1,44)=4.4, p<.05, \eta^{2}=.09$. No

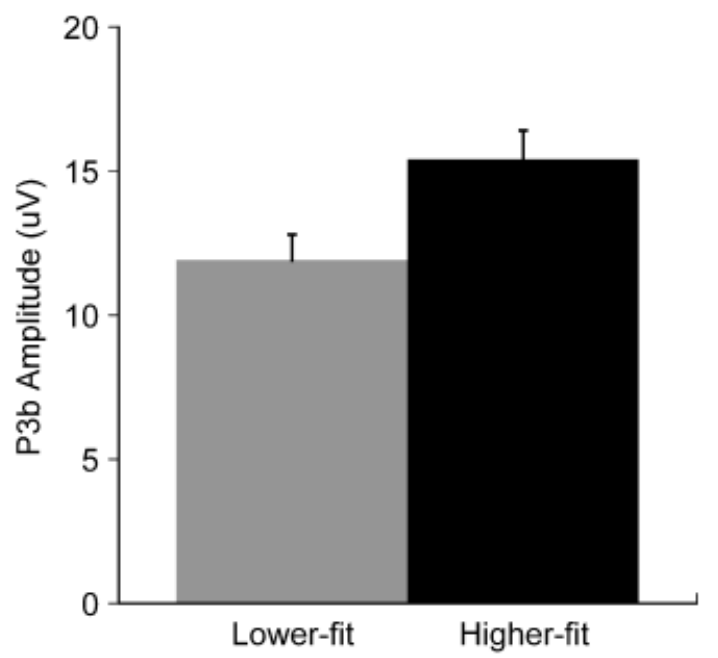

Figure 3. Mean (+1 SE) P3b amplitude from the oddball target stimulus for each aerobic fitness group collapsed over age and electrode.

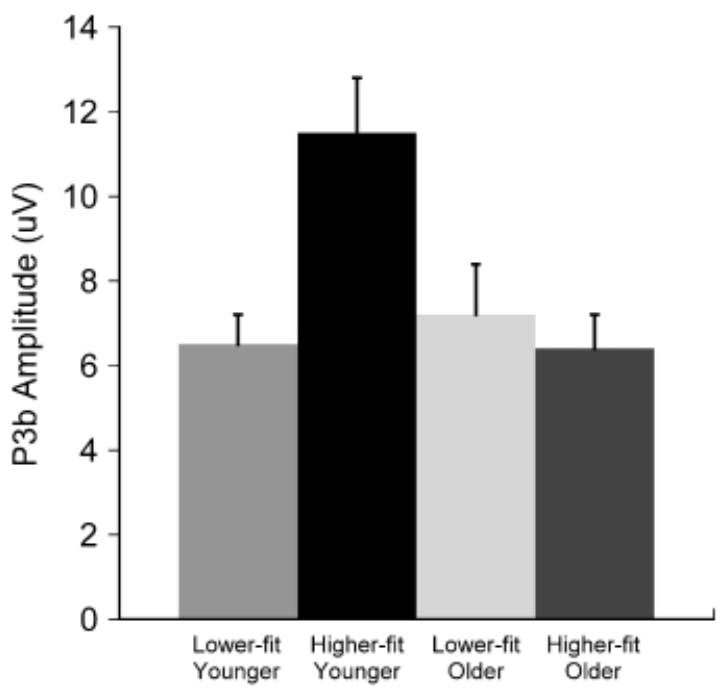

Figure 4. Mean (+1 SE) P3b amplitude from the three-stimulus oddball target for each aerobic fitness and age group collapsed over electrode.

other effects were observed for the three-stimulus target or distracter stimuli in the three-stimulus task.

\section{P3b Latency}

Oddball target P3b latency was shorter for younger $(\mathrm{M}=384, \mathrm{SE}=7.0 \mathrm{~ms})$ compared to older $(\mathrm{M}=410, \mathrm{SE}=7.4$ ms) participants, $F(1,44)=6.7, p<.05, \eta^{2}=.13$. No effects were observed for the three-stimulus target.

\section{P3a Latency}

The distracter from three-stimulus task produced shorter P3a latencies for younger $(\mathrm{M}=338, \mathrm{SE}=5.7 \mathrm{~ms})$ compared to older $(\mathrm{M}=377, \mathrm{SE}=6.0 \mathrm{~ms})$ participants, $F(1,44)=21.5, p<.001$, $\eta^{2}=.33$, Further, a fitness $\times$ site interaction was obtained, $F(6,39)=3.1, p<.05, \eta^{2}=.07$, with post-hoc tests indicating no significant differences between groups at any electrode site, $t(46) \leq 2, p \geq .05$ (all comparisons).

\section{Discussion}

For a relatively easy perceptual stimulus discrimination task, higher-fit individuals yielded shorter RT and larger P3b amplitude compared to their lower-fit age-matched counterparts. However, for a more difficult perceptual stimulus discrimination task, larger P3b amplitudes were found only in higher-fit younger adults, suggesting that aerobic fitness does not protect against age-related cognitive deficits. Fitness also did not alter the P3a component, suggesting that attentional orienting processes are unaffected by fitness. Thus, fitness appears to selectively affect the attentional system, which differs across the adult lifespan.

\section{Age and ERP Changes}

These findings corroborate previous age-related changes in ERP components with cognitive aging relating to reductions in the ability to orient to, allocate attention toward, and process task relevant information. Specifically, older adults exhibited reduced N2 amplitude and a more diffuse pattern of activation with increased perceptual task difficulty (Enoki, Sanada, Yoshinaga, Oka, \& Ohtahara, 1993; Iragui, Kutas, Mitchiner, \& Hillyard, 1993), and longer N2 latency during the three-stimulus target condition (Anderer, Semlitsch, \& Saletu, 1996; Picton et al., 
1984). These findings suggest that older adults exhibited a reduced ability to differentiate standard and target stimuli during the three-stimulus oddball task (Folstein \& Van Petten, 2008), with the reduced amplitude and lengthened latency found here for the $\mathrm{P} 3 \mathrm{a}$ and $\mathrm{P} 3 \mathrm{~b}$ for older relative to younger adults providing additional support for this view (Fjell \& Walhovd, 2001; Walhovd et al., 2008).

\section{Fitness, Cognitive Aging, and P3a/P3b}

The present findings also are consonant with previous behavioral and neuroelectric chronic physical activity or fitness effects on cognition and extend them to task difficulty and attentional orienting (Hillman et al., 2002, 2004, 2006a; Polich \& Lardon, 1997). In this framework, higher-fit individuals exhibit facilitation of behavioral performance during the simple stimulus discrimination task with increased P3b amplitude. However, despite these similarities and contrary to the a priori hypothesis, no effect of fitness on P3b latency was obtained. It seems likely that the cognitive tasks employed contributed to this outcome, as shorter P3b latency typically has been observed for higher active relative to lower active individuals for tasks requiring increased executive control (Hillman et al., 2004, 2006a). The defining characteristics that determine strong P3b latency changes for perceptual discrimination compared to executive control task conditions are yet to be determined but are likely to reflect variation in focal attention and allocation of attentional resource requirements (Polich, 2007).

Cardiorespiratory fitness may be associated with an increased ability to suppress extraneous neural activity to facilitate attentional processing, resulting in shorter RT for a stimulus discrimination task with low perceptual demands. As cardiorespiratory fitness is related to the increased health of neural tissue vital to attentional processes (Colcombe et al., 2004), an increased ability to allocate attentional resources for higher- relative to lower-fit participants due to the health of the frontal, temporal, and parietal cortices may underlie the present behavioral and ERP findings (Kramer \& Hillman, 2006). General improvements in cognition regardless of age were observed with increased fitness for the easy visual perceptual oddball task, whereas the relationship between fitness and cognitive aging suggested by the three-stimulus discrimination task is more specialized. Cardiorespiratory fitness was associated with increased $\mathrm{P} 3 \mathrm{~b}$ amplitude only for the higher-fit younger adults relative to all other groups. This result was counter to the $a$ priori hypothesis and suggests that higher-fit older adults may be unable to overcome deficits associated with cognitive aging. For example, loss of grey and white matter that is especially predominant in the prefrontal cortex (Colcombe et al., 2004). Thus, cognitive decline from the depletion of available neural structures could affect attentional resource availability and result in a reduced ability to inhibit extraneous neural activity when task demands increase due to perceptual difficulty.
The association between age and fitness with attentional processing capability appears to be mediated by task difficulty. However, fitness does not appear to exert an influence on aspects of attentional orienting, as no effects of P3a amplitude or latency changes relative to cardiorespiratory fitness were obtained. Fitness-related changes in cognitive aging therefore do not originate from a general change in attention but appear specific to attentional processing. While the mechanisms underlying fitnessrelated aging differences in attentional processing remain unclear, results from animal studies have suggested a link between aerobic exercise and neuronal proliferation (Cotman \& EngesserCesar, 2002) as well as increases in monoamines such as norepinephrine and dopamine (Brown et al., 1979; Dunn, Reigle, Youngstedt, Armstrong, \& Dishman, 1996; MacRae, Spirduso, Cartee, Farrar, \& Wilcox, 1987). Additionally, as noted above, human findings indicate that chronic aerobic training may mediate, and in some cases even reverse, age-related decreases in neuronal tissue loss in the frontal, parietal, and temporal cortices (Colcombe et al., 2004).

In this context, neuropharmacological evidence suggests that P3a may be related to the dopaminergic system (Polich \& Criado, 2006), while P3b may be related to the locus coeruleus-norepinephrine system (Nieuwenhuis, Aston-Jones, \& Cohen, 2005). Given the present findings that only the P3b was modulated by fitness, the mechanisms underlying fitness-related differences in attention may be due to differences in the locus-coeruleus-norepinephrine system. Since differential age effects were evident during the task requiring greater perceptual demands, how this system may be influenced by fitness across the lifespan remains an open question. However, the present study was cross-sectional in design, and attributes such as genetic predisposition, variation in personality, individual differences, task efficacy, etc., may be associated with the self-selection of participants into specific fitness groups (Polich, 2007). Thus, future research using randomized control designs are necessary to fully elucidate this relationship.

\section{Conclusion}

Fitness-related differences in cognitive aging may be specific to attentional processing, which can be modulated by cardiorespiratory fitness level under low perceptual discrimination difficulty tasks without regard to age. Under conditions of higher perceptual difficulty, cardiorespiratory fitness only affected attentional processing in younger adults as reflected by ERP measures. In sum, the positive association between fitness and cognition may be mediated by both age and task difficulty, so that specific attentional processing characteristics, rather than a more generalized mechanism, are influenced by these variables.

\section{REFERENCES}

American College of Sports Medicine (2000). ACSM's guidelines for exercise testing and prescription $\left(6^{\text {th }} \mathrm{ed}\right)$. New York: Lippincott Williams $\&$ Wilkins.

Anderer, P., Semlitsch, H. V., \& Saletu, B. (1996). Multichannel auditory event-related brain potentials: Effects of normal aging on the scalp distribution of $\mathrm{N} 1, \mathrm{P} 2, \mathrm{~N} 2$, and $\mathrm{P} 300$ latencies and amplitudes. Electroencephalography and Clinical Neurophysiology, $99,458-472$.
Azizian, A., \& Polich, J. (2007). Evidence for attentional gradient in the serial position memory curve from event-related potentials. Journal of Cognitive Neuroscience, 19, 2071-2081.

Bashore, T. R., \& Ridderinkhof, K. R. (2002). Older age, traumatic brain injury, and cognitive slowing: Some convergent and divergent findings. Psychological Bulletin, 128, 151-198.

Beck, A. T., Ward, C., \& Mendelson, M. (1961). Beck Depression Inventory (BDI). Archives General Psychiatry, 4, 561-571. 
Borg, G. (1970). Perceived exertion as an indicator of somatic stress. Scandinavian Journal of Rehabilitation Medicine, 2, 92-98.

Brown, B. S., Payne, T., Kim, C., Moore, G., Krebs, P., \& Martin, W. (1979). Chronic response of rat brain norepinephrine and serotonin levels to endurance training. Journal of Applied Physiology, 46, 19-23.

Celesia, G. G. (1986). EEG and event-related potentials in aging and dementia. Clinical Neurophysiology, 3, 9-11.

Colcombe, S. J., \& Kramer, A. F. (2003). Fitness effects on the cognitive function of older adults: A meta-analytic study. Psychologico Science, $14,125-130$.

Colcombe, S. J., Kramer, A. F., Erickson, K. I., Scalf, P., McAuley, E., Cohen, N. J., et al. (2004). Cardiovascular fitness, cortical plasticity, and aging. Proceedings of the National Academy of Sciences of the USA, 101, 3316-3321.

Colcombe, S. J., Erickson, K. I., Raz, N., Webb, A. G., Cohen, N. J., McAuley, E., et al. (2003). Aerobic fitness reduces brain tissue loss in aging humans. Journal of Gerontology: Medical Sciences, 58, 176180.

Compumedics Neuroscan (2003). Offline analysis of acquired data (SCAN 4.3 - Vol. II, EDIT 4.3). [Software Manual]. El Paso, TX.

Conroy, M. A., \& Polich, J. (2007). Normative variation of P3a and P3b from a large sample $(N=120)$ : Gender, topography, and response time. Journal of Psychophysiology, 21, 22-32.

Cotman, C. W., \& Engesser-Cesar, C. (2002). Exercise enhances and protects brain function. Exercise and Sport Sciences Reviews, 30, 7579.

Donchin, E. (1981). Surprise! ... Surprise? Psychophysiology, 18, 493513.

Donchin, E., \& Coles, M. G. H. (1988). Is the P300 component a manifestation of context updating? Behavioral and Brain Sciences, 11, 357-374.

Donchin, E., Karis, D., Bashore, T. R., Coles, M. G. H., \& Gratton, G. (1986). Cognitive psychophysiology: Systems, processes, and applications. In: M. G. H. Coles, E. Donchin, \& S. Porges (Eds.), Psychophysiology: Systems, processes, and applications (pp. 309-330). New York: The Guilford Press.

Duncan-Johnson, C. C. (1981). P3 latency: A new metric of information processing. Psychophysiology, 18, 207-215.

Dunn, A. L., Reigle, T. G., Youngstedt, S. D., Armstrong, R. B., \& Dishman, R. K. (1996). Brain norepinephrine and metabolites after treadmill training and wheel running in rats. Medicine and Science in Sports and Exercise, 28, 204-209.

Enoki, H., Sanada, S., Yoshinaga, H., Oka, E., \& Ohtahara, S. (1993). The effects of age on the N200 component of auditory event-related potentials. Cognitive Brain Research, 1, 161-167.

Fjell, A., \& Walhovd, K. (2001). P300 and neuropsychological tests as measures of aging: Scalp topography and cognitive changes. Brain Topography, 14, 25-40.

Folstein, M. F., Folstein, S. E., \& McHugh, P. R. (1975). Mini-mental state: A practical method for grading the cognitive state of patients for the clinician. Journal of Psychiatric Research, 12, 189-198.

Folstein, J. R., \& Van Petten, C. (2008). Influence of cognitive control and mismatch on the N2 component of the ERP: A review. Psychophysiology, 45, 152-170.

Friedman, D., Simpson, G., \& Hamberger, M. (1993). Age-related changes in scalp topography to novel and target stimuli. Psychophysiology, 30, 383-396.

Goodin, D. S., Squires, K. C., Henderson, B. H., \& Starr, A. (1978). Age-related variations in evoked potentials to auditory stimuli in normal human subjects. Electroencephalography \& Clinical Neurophysiology, 44, 447-458.

Hagen, G. F., Gatherwright, J. R., Lopez, B. A., \& Polich, J. (2006). P3a from visual stimuli: Primary task difficulty effects. International Journal of Psychophysiology, 59, 8-14.

Hartikainen, K., \& Knight, R. T. (2003). Lateral and orbital prefrontal cortex contributions to attention. In J. Polich (Eds.), Detection of change event-related potential and fMRI findings (pp. 99-116). Boston: Kluwer Academic Press.

Hillman, C. H., Buck, S. M., \& Themanson, J. T. (in press). Physical activity and neurocognitive function across the lifespan. In W. Chodzko-Zajko \& A. F. Kramer (Eds.), Active living, cognitive functioning, and aging (Vol. 3). Champaign, IL: Human Kinetics.

Hillman, C. H., Belopolsky, A. V., Snook, E. M., Kramer, A. F., \& McAuley, E. (2004). Physical activity and executive control: Impli- cations for increased cognitive health during older adulthood. Research Quarterly for Exercise and Sport, 75, 176-185.

Hillman, C. H., Kramer, A. F., Belopolsky, A. V., \& Smith, D. P. (2006a). A cross-sectional examination of age and physical activity on performance and event-related brain potentials in a task switching paradigm. International Journal of Psychophysiology, 59, $30-39$.

Hillman, C. H., Motl, R. W., Pontifex, M. B., Posthuma, D., Stubbe, J. H., Boomsma, D. I., \& de Geus, E. J. C. (2006b). Physical activity and cognitive function in a cross-section of younger and older community-dwelling individuals. Health Psychology, 25, 678-687.

Hillman, C. H., Weiss, E. P., Hagberg, J. M., \& Hatfield, B. D. (2002). The relationship of age and cardiovascular fitness to cognitive and motor processes. Psychophysiology, 39, 303-312.

Hillman, C. H., Erickson, K. I., \& Kramer, A. F. (2008). Be smart, exercise your heart: Exercise effects on brain and cognition. Nature Reviews Neuroscience, 9, 58-65.

Ilan, A. B., \& Polich, J. (1999). P300 and response time from a manual Stroop task. Clinical Neurophysiology, 110, 367-373.

Iragui, V. J., Kutas, M., Mitchiner, M., \& Hillyard, S. A. (1993). Effects of aging on event-related potentials and reaction times in an auditory oddball task. Psychophysiology, 30, 10-22.

Jasper, H. H. (1958). The ten-twenty electrode system of the International Federation. Electroencephalography and Clinical Neurophysiology, 10, 371-375.

Johnson, R. (1993). On the neural generators of the P300 component of the event-related potential. Psychophysiology, 30, 90-97.

Kaufman, A. S., \& Kaufman, N. L. (1990). Kaufman Brief Intelligence Test manual. Circle Pines, MN: American Guidance Service.

Knight, R. T. (1984). Decreased response to novel stimuli after prefrontal lesions in man. Electroencephalography and Clinical Neurophysiology, $59,9-20$.

Kok, A. (2001). On the utility of $\mathrm{P} 3$ amplitude as a measure of processing capacity. Psychophysiology, 38, 557-577.

Kramer, A. F., \& Erickson, K. I. (2007). Capitalizing on cortical plasticity: influences of physical activity on cognition and brain function. Trends in Cognitive Sciences, 11, 342-348.

Kramer, A. F., \& Hillman, C. H. (2006). Aging, physical activity, and neurocognitive function. In E. Acevado \& P. Ekkekakis (Eds.). Psychobiology of exercise and sport (pp. 45-59). Champaign, IL: Human Kinetics.

Kutas, M., McCarthy, G., \& Donchin, E. (1977). Augmenting mental chronometry: The P300 as a measure of stimulus evaluation time. Science, 197, 792-795.

MacRae, P. G., Spirduso, W. W., Cartee, G. D., Farrar, R. P., \& Wilcox, R. E. (1987). Endurance training effects on striatal $\mathrm{D}_{2}$ dopamine receptor binding and striatal dopamine metabolite levels. $\mathrm{Neu}$ roscience Letters, 79, 138-144.

Magliero, A., Bashore, T. R., Coles, M. G. H., \& Donchin, E. (1984). On the dependence of P300 latency on stimulus evaluation processes. Psychophysiology, 21, 171-186.

Milham, M. P., Erickson, K. I., Banich, M. T., Kramer, A. F., Webb, A., Wszalek, T., \& Cohen, N. J. (2002). Attentional control in the aging brain: Insights from an fMRI study of the stroop task. Brain and Cognition, 49, 277-296.

Nieuwenhuis, S., Aston-Jones, G., \& Cohen, J. (2005). Decision making, the P3, and the locus coeruleus-norepinephrine system. Psychological Bulletin, 131, 510-532.

Oldfield, R. C. (1971). The assessment and analysis of handedness: The Edinburgh inventory. Neuropsychologia, 9, 97-113.

Picton, T. W., Stuss, D. T., Champagne, S. C., \& Nelson, R. F. (1984). The effects of age on human event-related potentials. Psychophysiology, 21, 312-325.

Polich, J. (1987). Task difficulty, probability and inter-stimulus interval as determinants of P300 from auditory stimuli. Electroencephalography and Clinical Neurophysiology, 63, 251-259.

Polich, J. (1996). Meta-analysis of P3 normative aging studies. Psychophysiology, 33, 334-353.

Polich, J. (2004). Clinical application of the P300 event-related potential. Physical Medicine and Rehabilitation Clinics, 15, 133-161.

Polich, J. (2007). Updating P300: An integrative theory of P3a and P3b. Clinical Neurophysiology, 118, 2128-2148.

Polich, J. (2008). Neuropsychology of P300. In S. J. Luck \& E. S. Kappenman (Eds.). Handbook of event-related potential components. New York: Oxford University Press, in press. 
Polich, J., \& Criado, J. R. (2006). Neuropsychology and neuropharmacology of P3a and P3b. International Journal of Psychophysiology, 60, $172-185$.

Polich, J., \& Heine, M. R. D. (1996). P3 topography and modality effects from a single-stimulus paradigm. Psychophysiology, 33, 747-752.

Polich, J., \& Lardon, M. (1997). P300 and long term physical exercise. Electroencephalography and Clinical Neurophysiology, 103, 493-498.

Reuter-Lorenz, P. A. (2002). New visions of the aging mind and brain. Trends in Cognitive Sciences, 6, 394-400.

Rushby, J. A., Barry, R. J., \& Doherty, R. J. (2005). Separation of the components of the late positive complex in an ERP dishabituation paradigm. Clinical Neurophysiology, 116, 2363-2380.

Squires, N., Squires, K., \& Hillyard, S. (1975). Two varieties of long-latency positive waves evoked by unpredictable auditory stim- uli in man. Electroencephalography and Clinical Neurophysiology, 38, $387-401$.

Thomas, S., Reading, J., \& Shephard, R. J. (1992). Revision of the Physical Activity Readiness Questionnaire (PAR-Q). Canadian Journal of Sport Sciences, 17, 338-345.

Verleger, R. (1997). On the utility of P3 latency as an index of mental chronometry. Psychophysiology, 34, 131-156.

Walhovd, K. B., Rosquist, H., \& Fjell, A. M. (2008). P300 amplitude age reductions are not caused by latency jitter. Psychophysiology, 45, $545-553$.

(Received April 29, 2008; ACCEPTED July 1, 2008) 